\title{
The Dipeptidyl Peptidase-4 Inhibitor Teneligliptin Reduces Aortic Damage from Hypercholesterolaemia in Apolipoprotein E-Deficient Mice
}

\author{
Ying Zhang ${ }^{a} \quad N^{2}$ Wang ${ }^{a}$ Liyue Zhug Yingshu Liuc ${ }^{c}$ Zuowei Pei ${ }^{d}$ \\ Guan Wang ${ }^{\text {e }}$ Lin Luo $^{f}$ Hongyang Liub \\ ${ }^{a}$ Department of Cardiology and ${ }^{b}$ Heart Intensive Care Unit, The First Affiliated Hospital \\ of Dalian Medical University, ${ }^{C}$ Department of Endocrinology, Dalian Municipal Central \\ Hospital, ${ }^{\mathrm{d}}$ Department of Cardiology and ${ }^{\mathrm{e}}$ International Medical Department, Affiliated \\ Zhongshan Hospital of Dalian University, and ${ }^{\mathrm{f}}$ Department of Central Intensive Care \\ Unit (ICU), The Second Affiliated Hospital of Dalian Medical University, Dalian, and \\ ${ }^{9}$ Rehabilitation Center, Zhejiang Hospital, Hangzhou, China
}

\begin{abstract}
What Is It about?
In this study, we evaluated whether the dipeptidyl peptidase-4 inhibitor teneligliptin reduced kidney damage in hypercholesterolaemia. Lectin-like oxidized low-density lipoprotein receptor-1 (LOX-1) induced aortic damage. Teneligliptin downregulates LOX-1 gene and protein expression via Pho-ERK signal transduction in aortic tissue. Teneligliptin reduces aortic damage according to decreased lipid deposition and inflammation. Usually, the dipeptidyl peptidase-4 inhibitor is used in the management of type 2 diabetes mellitus, and our study found that teneligliptin reduced aortic damage in hypercholesterolaemia.
\end{abstract}

\section{Keywords}

Hypercholesterolaemia $\cdot$ Aortic damage $\cdot$ Dipeptidyl peptidase-4 $\cdot \mathrm{ApoE}^{-/-}$mice

\begin{abstract}
Objective: Hypercholesterolaemia is a well-established risk factor for blood vessel damage, which can lead to cardiovascular diseases. An abundance of clinical data show that dipeptidyl peptidase-4 inhibitors protect against aortic damage in patients with diabetes. The goal of this study was to investigate the possible protective effects of teneligliptin against aortic damage in apolipoprotein E knockout (ApoE ${ }^{-/}$) mice. Methods: Eight-week-old male ApoE ${ }^{-/-}$mice were randomly divided into 3 groups: a control group fed a normal diet, a high-cholesterol diet (HD group), and an HD diet mixed with teneligliptin (HD + Tene group), and all the groups were fed with the different treatments for 6 weeks. Results and Conclusion: The metabolic characteristics of total cholesterol, low-density lipoprotein-cholesterol, and high-sensitivity
\end{abstract}


C-reactive protein were lower in $\mathrm{ApoE}^{-/-} \mathrm{HD}+$ Tene mice than in $\mathrm{ApoE^{-/- }} \mathrm{HD}$ mice. Lectin-like oxidized low-density lipoprotein receptor-1 (LOX-1) gene and protein expression were lower in the aortic tissue of $\mathrm{ApoE}^{-/-} \mathrm{HD}+$ Tene mice than in $\mathrm{ApoE}^{-/-} \mathrm{HD}$ mice. IL- 6 and TNF- $\alpha$ gene expression were lower in $\mathrm{ApoE}^{-/-} \mathrm{HD}+$ Tene mice than in $\mathrm{ApoE}^{-/-} \mathrm{HD}$ mice. These results indicate that teneligliptin may provide a potential therapeutic target for the aortic damage from hypercholesterolaemia.

(c) 2017 The Author(s)

Published by S. Karger AG, Basel

\section{Introduction}

$\mathrm{ApoE}^{-/-}$mice are considered a well-accepted model of hypercholesterolaemia [1]. Hypercholesterolaemia leads to the development of cardiovascular disease, which involves disorders of the heart and blood vessels, and causes various fatal events [2, 3].

In $\mathrm{ApoE}^{-/-}$mice, hypercholesterolaemia accelerates lipid deposition, atherosclerosis, and chronic inflammation $[4,5]$. However, the underlying pathophysiological mechanisms of the relationship between hypercholesterolaemia and aortic injury are not yet fully understood. Dipeptidyl peptidase-4 (DPP-4), also known as lymphocyte cell surface marker CD26, exists as a smaller soluble form in blood plasma. DPP-4 is widely expressed on T and B cells, subsets of macrophages, haematopoietic stem cells, and haematopoietic progenitor cells, as well as on epithelial, endothelial, and acinar cells of a variety of tissues [6, 7]. The complex biological roles of DPP-4 include cell membrane-associated activation of intracellular signal transduction pathways, cell-to-cell interaction, and enzymatic activity [8]. Inhibition of the DPP-4 system is a new approach to the management of type 2 diabetes by virtue of its effects on extending the half-life of glucose-dependent insulinotropic peptide (GLP-1) and glucagonlike peptide-1 [9].

DPP-4 inhibitors have been demonstrated to play a protective role in cardiovascular diseases, including hypertension, atherosclerosis, and peripheral vascular disease through both GLP-1-dependent and -independent effects [10-12]. Meta-analyses suggest a potentially beneficial effect of DPP-4 inhibitors on cholesterol, which could contribute to a reduction in cardiovascular risk $[13,14]$. Much clinical data suggests that teneligliptin is associated with improvements in left ventricular function, particularly diastolic and endothelial functions [15]. However, the function of teneligliptin in hypercholesterolaemia-induced aortic injury is not clear.

\section{Materials and Methods}

All animal studies were approved by the Animal Studies Committee of the First Affiliated Hospital of Dalian Medical University. ApoE-/- (B6.129P2-Apoetm1Unc/J) mice were purchased from Shanghai Slac Laboratory Animal Co., Ltd. (Shanghai, China). All mice were housed in a room with a 12:12-h light-dark cycle, with room temperature maintained at $24^{\circ} \mathrm{C}$. At 8 weeks of age, the Apo: ${ }^{-/-}$male mice were randomly divided into 3 groups and fed with either a normal diet $(n=7)$, a high-cholesterol diet $(n=7)$, or teneligliptin $(20 \mathrm{mg} / \mathrm{kg} / \mathrm{day}$; Mitsubishi Tanabe Pharma, Osaka, Japan) plus a high-cholesterol diet $(n=7)$. The high-cholesterol diet contained $1.5 \%$ cholesterol and $15 \%$ fat. The experimental diet was purchased from the Shanghai Slac Laboratory Animal Co., Ltd. Each group was fed their diet for 6 weeks. Blood samples were obtained from the inferior vena cava, collected in serum tubes, and stored at $-80^{\circ} \mathrm{C}$ until used. Coronal sections of the aorta were fixed in $10 \%$ formalin and then embedded in paraffin for histological evaluation. The remainder of the aorta was snap-frozen in liquid 
nitrogen for mRNA or immunohistochemical analysis. All animal experiments were performed in accordance with the Guide for the Care and Use of Laboratory Animals. The study was approved by the ethical committee of the First Affiliated Hospital of Dalian Medical University.

\section{Biochemical Measurements}

Total cholesterol (TC), low-density lipoprotein-cholesterol (LDL-C), and high-sensitivity $\mathrm{C}$-reactive protein (hs-CRP) were measured using an automatic analyser (Dimension, Wilmington, DE, USA).

\section{Morphologic Analysis and Immunohistochemistry}

The aorta was dissected free from the surrounding connective tissue. Aorta samples were collected and fixed in 4\% paraformaldehyde. Samples were embedded in paraffin and then were cut into slices using a microtome (Leica RM 2235 or Leica CM1850UV; Leica, Solms, Germany). Slices were then mounted onto glass slides and histological examinations were performed.

Immunohistochemistry was performed using the Histone Simple Stain Kit (Nichirei, Tokyo, Japan) according to the manufacturer's instructions. Briefly, paraffin-embedded sections were deparaffinized with xylene and then rehydrated in a descending series of ethanol washes. The sections were treated for 15 min with $3 \% \mathrm{H}_{2} \mathrm{O}_{2}$ in methanol to inactivate endogenous peroxidases and then incubated at room temperature for $1 \mathrm{~h}$ with primary antibodies to collagen IV (rabbit anti-collagen IV antibody, 1:500; Abcam, England) and LOX-1 (rabbit anti-LOX-1 antibody, 1:250; Abcam). All sections were observed under an Olympus B $\times 40$ upright light microscope (Olympus, Tokyo, Japan).

\section{RNA Isolation and Real-Time RT-PCR}

Total RNA was isolated from aorta using ISOGEN (Nippon Gene, Tokyo, Japan) according to the manufacturer's protocol. Complementary DNA (cDNA) was synthesized from total RNA using a first-strand cDNA synthesis kit (SuperScript VILO cDNA Synthesis Kit; Life Technologies, Carlsbad, CA, USA) according to the manufacturer's protocol. Gene expression was analysed quantitatively by real-time RT-PCR using fluorescent SYBR Green technology (Light Cycler; Roche Molecular Biochemicals). $\beta$-Actin cDNA was amplified and quantitated in each cDNA preparation in order to normalize the relative amounts of the target genes. Primer sequences are listed in Table 1.

\section{Western Blotting for Aortic Tissue}

Proteins were extracted from renal cortical tissues using radio immunoprecipitation assay buffer (P0013B; Beyotime, Shanghai, China). Samples were electrophoresed on 10\% SDS-PAGE gel, and proteins were transferred to polyvinylidene fluoride membrane (Immobilon, Millipore, Billerica, MA, USA). Membranes were blocked in Tris-buffered saline with $0.1 \%$ Tween-20 containing $5 \%$ skim milk, and then were incubated in primary antibody diluent (P0023A; Beyotime) and gently shaken overnight at $4{ }^{\circ} \mathrm{C}$. Primary antibodies against LOX-1 (rabbit anti-LOX-1 polyclonal antibody;1:250; Abcam), phosphor-Erk (rabbit antiphosphor-Erk, polyclonal antibody 1:1,000; Cell Signaling Technology), and anti- $\beta$-actin antibody (1:1,000; Cell Signaling Technology) were used. Membranes were then incubated with secondary antibody (anti-rabbit Ig-G, 1:1,000; Cell Signaling Technology) for $1 \mathrm{~h}$. This analysis was carried out independently 3 times. Protein levels are expressed as protein $/ \beta$-actin ratios to minimize loading differences. The relative signal intensity was quantified using NIH ImageJ software. 
Table 1. Primer oligonucleotide sequences
(C) 2017 The Author(s). Published by S. Karger AG, Basel www.karger.com/bmh

Zhang et al.: Teneligliptin Reduces Aortic Damage from Hypercholesterolaemia

\begin{tabular}{ll}
\hline Gene & Primers \\
\hline L0X-1 & F: 5'-CAAAGTCTCCCAACCAACCTGCAA-3' \\
& R: 5'-ACATCCTGTCTTTCATGCGGCAAC-3' \\
3-Actin & F: 5'-CGATGCCCTGAGGGTCTTT-3' \\
& R: 5'-TGGATGCCACAGGATTCCAT-3' \\
SR-A1 & F: 5'-GTTAAAGGTGATGGGGGACA-3' \\
& R: 5'-TCCCCTTCTCTCCCTTTTGT-3' \\
CD36 & F: 5'-CCTTAAAGGAATCCCCGTGT-3' \\
& R: 5'-TGCATTTGCCAATGTCTAGC-3' \\
ABCA1 & F: 5'-AGCCAGAAGGGAGTGTCAGA-3' \\
& R: 5'-CATGCCATCTGGGTAAACCT-3' \\
TNF- $\alpha$ & F: 5'-TCTCATGCACCACCATCAAGGACT-3' \\
& R: 5'-ACCACTCTCCCTTTGCAGAACTCA-3' \\
IL-6 & F: 5'-TACCAGTTGCCTTCTTGGGACTGA-3' \\
& R: 5'-TAAGCCTCCGACTTGTGAAGTGGT-3'
\end{tabular}

LOX-1, lectin-like oxidized low-density lipoprotein receptor-1; SR-A, scavenger receptor-A; ABCA1, ATP-binding cassette transporter A1.

Table 2. Metabolic data from the 4 groups after 6 weeks of dietary treatment

\begin{tabular}{lccc}
\hline & $\mathrm{ApoE}^{-/-} \mathrm{ND}(n=7)$ & $\mathrm{ApoE}^{-/-} \mathrm{HD}(n=6)$ & $\mathrm{ApoE}^{-/-} \mathrm{HD}+$ Tene $(n=7)$ \\
\hline Body weight, g & $24.67 \pm 0.71$ & $23.92 \pm 0.83$ & $24.72 \pm 0.79$ \\
$\mathrm{TC}, \mathrm{mg} / \mathrm{dL}$ & $572.65 \pm 101.35^{*}$ & $2,302.73 \pm 326.62$ & $650.52 \pm 62.28^{*}$ \\
$\mathrm{LDL}-\mathrm{C}, \mathrm{mg} / \mathrm{dL}$ & $146.27 \pm 42.75^{*}$ & $663.52 \pm 92.13$ & $174 \pm 23.89^{*}$ \\
hs-CRP, ng/dL & $107.63 \pm 28.53^{* *}$ & $198.62 \pm 39.72$ & $120.61 \pm 23.65^{* *}$ \\
\hline
\end{tabular}

Data are expressed as means \pm SEM; $n=6-7$ per group. TC, total cholesterol; LDL-C, low-density lipoprotein cholesterol; hs-CRP, high-sensitivity C-reactive protein. ${ }^{*} p<0.01$ vs. ApoE ${ }^{-/-} \mathrm{HD}$; ${ }^{* *} p<0.05 \mathrm{vs}$. ApoE $^{-/-} \mathrm{HD}$.

\section{Statistical Analysis}

All data are presented as means \pm SEM. Statistical analysis was performed using SPSS software version 23.0 (SPSS Inc., Chicago, IL, USA). Intergroup variation was measured by 1 -way ANOVA and a subsequent Tukey test. The minimal level for significance was $p<0.05$.

\section{Results}

\section{Metabolic Characteristics}

The metabolic characteristics of $\mathrm{ApoE}^{-/-}$mice after 6 weeks of dietary treatment are summarized in Table 2. In the ApoE $\mathrm{E}^{-/-}$mice, TC and LDL were markedly increased in the HD group, but were significantly decreased in the HD + Tene group. There was no difference between the HD + Tene group and the normal diet group. Body weight did not differ among the 3 groups. Compared with the HD group, hs-CRP was significantly decreased in the HD + Tene group. Teneligliptin reduced LOX-1 gene expression in the aortic tissue of $\mathrm{ApoE}^{-/-}$mice with HD.

To investigate the mechanism of lipid accumulation in the aorta, aortic tissue gene expression of relevant receptors and the TP-binding cassette transporter A1 (ABCA1) were examined by RT-PCR. Compared with the normal diet group mice, LOX-1 gene expression was 


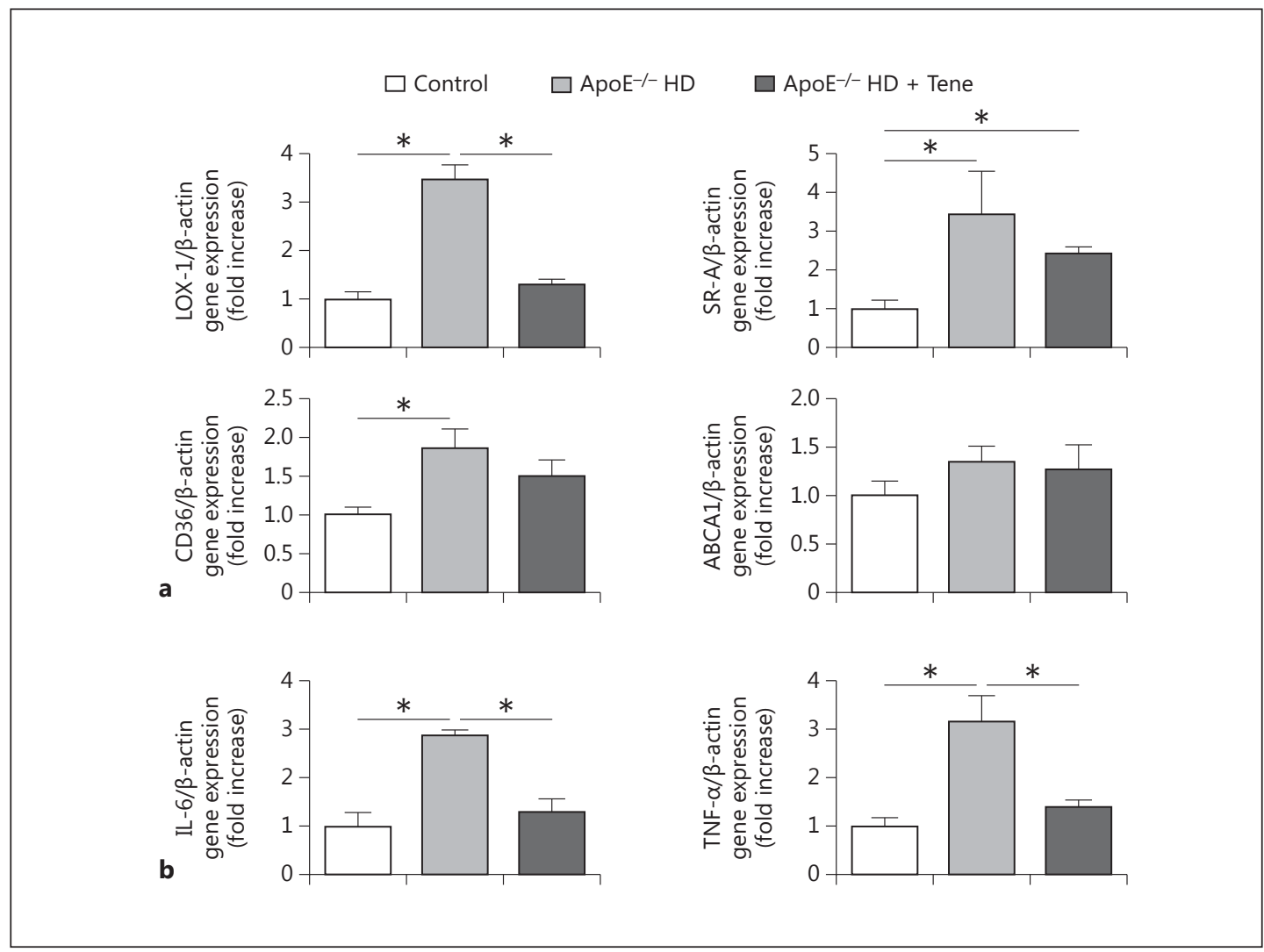

Fig. 1. Scavenger receptors and proinflammatory gene expression in the aortic tissue of the 3 groups after 6 weeks of different treatments. a Relative mRNA expression of LOX-1, SRA, CD36, and ABCA1 in the aortic tissue of each group after 6 weeks of different treatment. b Relative mRNA expression of IL- 6 and TNF- $\alpha$ in the aortic tissue of each groups after 6 weeks of dietary treatment. Data are expressed as the means \pm SEM; $n=$ 6-7 in each group. * $p<0.05$.

significantly increased in the aortic tissue of the $\mathrm{ApoE}^{-/-} \mathrm{HD}$ group mice. The increased expression of LOX-1 was suppressed in the $\mathrm{ApoE}^{-/-} \mathrm{HD}+$ Tene group. Compared with the normal diet group, expression of scavenger receptor-class A (SR-A) and CD36 were increased in the $\mathrm{ApoE}^{-/-} \mathrm{HD}$ mice; however, levels were similar to those of $\mathrm{ApoE}^{-/-} \mathrm{HD}+$ Tene mice. Expression of ABCA1 did not differ among the 3 groups (Fig. 1a). These results suggest that LOX-1, SR-A, and CD36 influence lipid accumulation in the aortic tissue of $\mathrm{ApoE}^{-/-} \mathrm{HD}$ mice. Compared to ApoE $\mathrm{E}^{-/-}$HD mice, LOX-1, in particular, appears to be a critical factor for mitigation of lipid accumulation in the aortic tissue of $\mathrm{ApoE}^{-/-} \mathrm{HD}+$ Tene mice.

Teneligliptin reduced TNF- $\alpha$ and IL-6 gene expression in the aortic tissue of $\mathrm{ApoE}^{-/-}$mice fed HD. To examine the involvement of proinflammatory cytokines in hypercholesterolaemic aortic damage, IL- 6 and TNF- $\alpha$ gene expression were measured by real-time PCR. Both IL- 6 and TNF- $\alpha$ were upregulated in ApoE $\mathrm{E}^{-/-} \mathrm{HD}$ mice; however, this upregulation was attenuated in $\mathrm{ApoE}^{-/-} \mathrm{HD}+$ Tene mice (Fig. 1b).

Teneligliptin reduced LOX-1 expression in aortic tissue assessed using immunohistochemistry. To evaluate LOX-1 expression in the aortic tissue, LOX-1 immunostaining was performed (Fig. 2). Compared with $\mathrm{ApoE}^{-/-} \mathrm{HD}$ mice, HD + Tene mice showed markedly reduced LOX-1 expression in aortic tissue. This result indicates that teneligliptin reduced LOX-1 expression in $\mathrm{ApoE}^{-/-} \mathrm{HD}$ mice. 
Fig. 2. LOX-1 expression in the aortic tissue of the 3 groups after 6 weeks of different treatments. Representative immunohistochemistry for LOX-1 in aortic tissue. Scale bar $=200 \mu \mathrm{m}$. Arrows indicate positive staining cells; $n=4$ in each group.
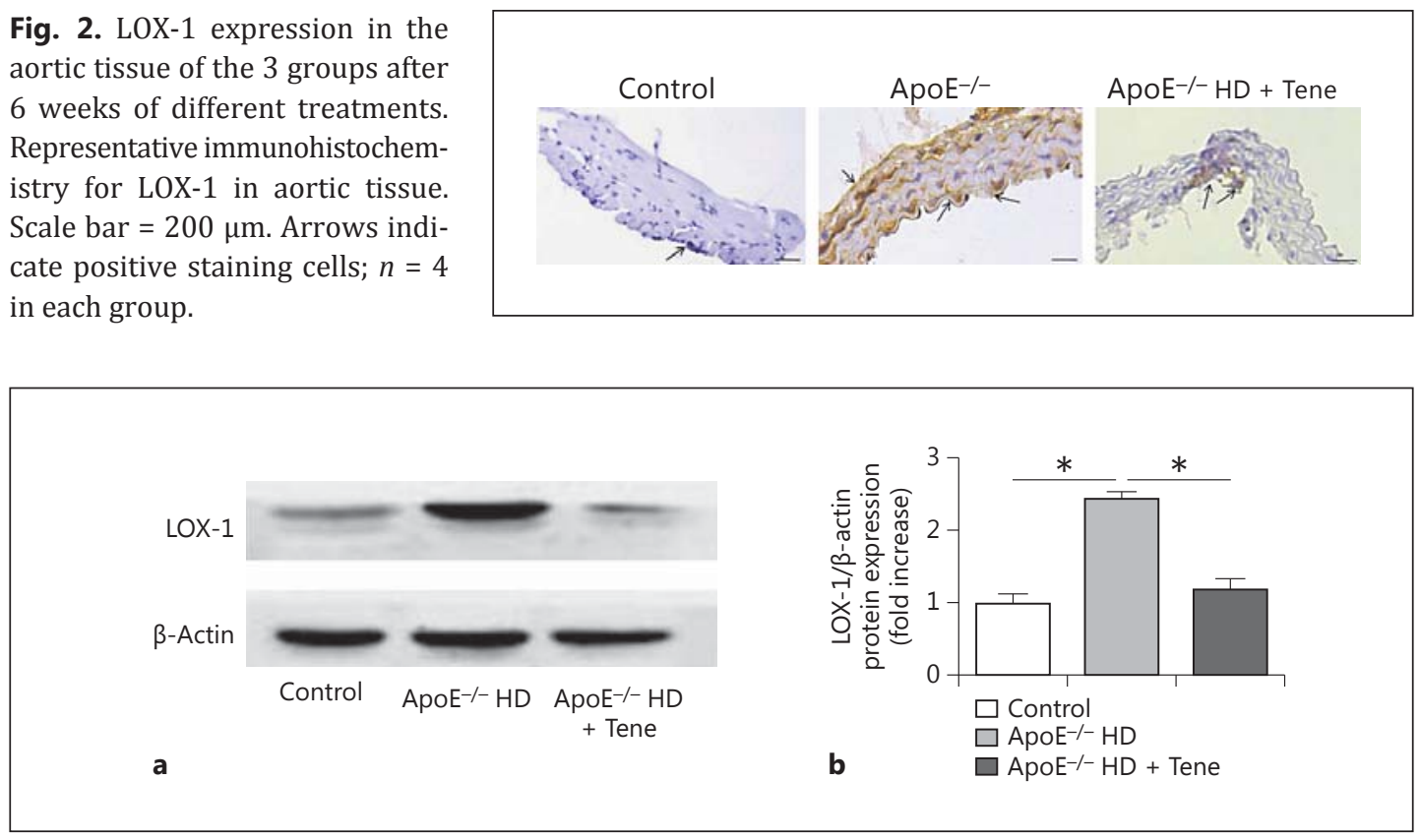

Fig. 3. LOX-1 protein expression in the aortic tissue of the 3 groups after 6 weeks of different treatments. a Immunoblotting for LOX-1 protein expression in aortic tissue. $\mathbf{b}$ Bar graph shows quantification of LOX-1 protein expression. Data are expressed as means \pm SEM; $n=3$ in each group; ${ }^{*} p<0.05 \mathrm{vs.} \mathrm{ApoE}^{-/-} \mathrm{HD}$.

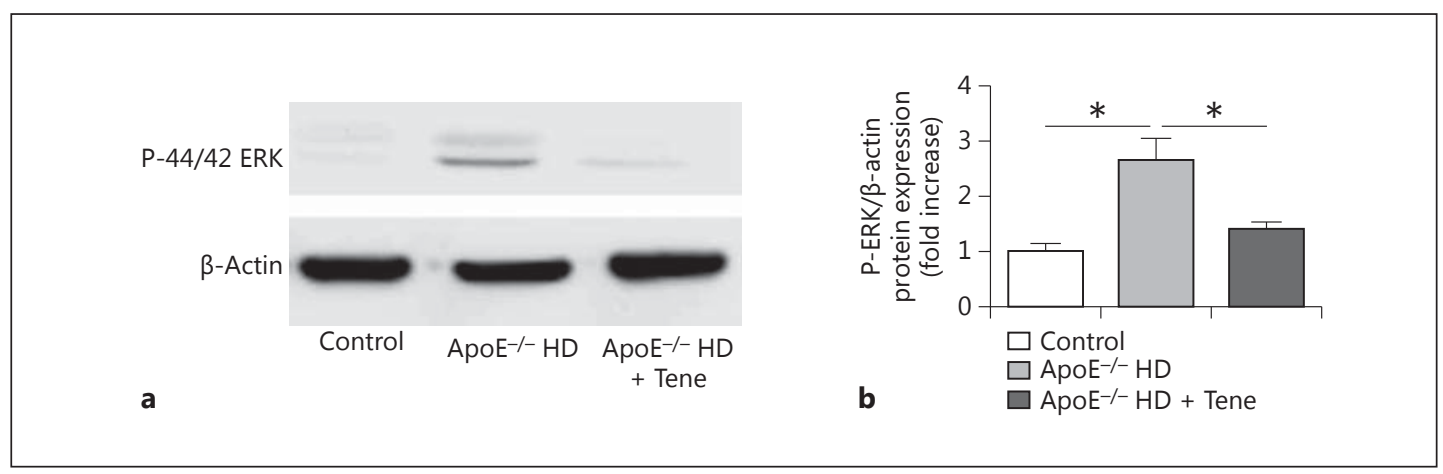

Fig. 4. Phosphor-ERK protein expression in the aortic tissue of the 3 groups after 6 weeks of different treatments. a Immunoblotting for phosphor-ERK protein expression in the aortic tissue. b Bar graph shows quantification of phosphor-ERK protein expression. Data are expressed as means \pm SEM; $n=3$ in each group; $* p<0.05$ vs. ApoE ${ }^{-/-}$HD.

Teneligliptin reduced LOX-1 protein expression in the aortic tissue of the $\mathrm{ApoE}^{-/-} \mathrm{HD}$ mice. To evaluate LOX-1 protein expression in the aortic tissue, LOX-1 protein immunoblotting was performed (Fig. 3a). We found that compared with the $\mathrm{ApoE}^{-/-}$HD group, LOX-1 protein was significantly suppressed in the $\mathrm{ApoE}^{-/-} \mathrm{HD}+$ Tene group (Fig. 3b).

Teneligliptin reduced phosphor-ERK expression in the aortic tissue of ApoE ${ }^{-/-} \mathrm{HD}$ mice. Protein kinases play a role in foam cell formation and lipid deposition, thus phosphor-ERK protein immunoblotting was performed (Fig. 4a). We found that compared with the ApoE $\mathrm{E}^{-/-}$ HD group, phosphor-ERK was significantly suppressed in the $\mathrm{ApoE}^{-/-} \mathrm{HD}+$ Tene group (Fig. 4b). 


\section{Discussion}

This study demonstrates that teneligliptin has a protective effect against the progressive lipid deposition and atherosclerosis elicited by hypercholesterolaemia.

According to metabolic characteristics, we found that compared with $\mathrm{ApoE}^{-/-} \mathrm{HD}+$ Tene mice, TC and LDL-c were increased in $\mathrm{ApoE}^{-/-} \mathrm{HD}$ mice. The major risk factors for atherosclerosis are increased blood levels of TC and LDL [16]. Jialal and Devaraj [17] reported that suppression of blood TC and LDL contributed to the prevention of atherosclerosis. Several clinical studies have indicated that the hs-CRP level reflects the instability of atherosclerotic lesions and can be used as a biomarker for risk stratification of cardiovascular events [1821]. Our results indicate that teneligliptin influences cholesterol metabolism and hs-CRP; however, further studies are needed to clarify the mechanisms.

Hypercholesterolaemia is a major independent risk factor for aortic damage and hyperlipidaemia promotes aortic lipid deposition and inflammation [22]. Cellular lipid homeostasis involves regulation of the influx, synthesis, catabolism, and efflux of lipids. An imbalance in these processes can result in conversion of macrophages and vascular smooth muscle cells into foam cells. This process is mediated by several independent pathways, including SR-A, class B (CD36), and LOX-1, and regulates expression of its target gene ABCA1 [23-25]. Proinflammatory genes (TNF- $\alpha$ and IL-6) were reported to be expressed at high levels and to contribute to cardiovascular disease in hyperlipidaemia [26, 27]. DPP-4 is a ubiquitous, type II cell surface glycoprotein and is widely expressed in all tissues [28]. Treatment with DPP-4 inhibitors, which increase GLP-1 levels, has been shown to exert numerous renoprotective effects. These effects include a reduction in blood glucose and lipid levels, inhibition of inflammation, and oxidative stress [29]. In the present study, we analysed gene expression of the LDL receptor and scavenger receptors which includes SR-A, CD36, and LOX-1. We found that LOX-1 gene expression was suppressed in the ApoE $\mathrm{E}^{-/-}$ HD + Tene group. LOX-1 was originally identified in endothelial cells and is a 50-kDa type II membrane glycoprotein that contains a short $\mathrm{N}$-terminal cytoplasmic domain, a single transmembrane domain, a short neck or stalk region, and an ox-LDL-binding C-terminal extracellular C-type lectin-like domain. On the cell surface, LOX-1 is comprised of 3 homodimers bound to ox-LDL, and plays a leading role in ox-LDL uptake and foam cell formation [30, 31]. In contrast, deletion of LOX-1 reduced uptake of oxidized LDL and inhibited atherosclerosis in high-cholesterol diet-fed mice [32]. Thus, suppression of LOX-1 expression in $\mathrm{ApoE}^{-/-} \mathrm{HD}+$ Tene mice may reduce lipid deposition. Teneligliptin also reduced LOX-1 protein expression in the aortic tissue of Apo: ${ }^{-/-} \mathrm{HD}$ mice. Compared with $\mathrm{ApoE}^{-/-} \mathrm{HD}+$ Tene mice, proinflammatory gene (TNF- $\alpha$ and IL-6) expression was also reduced in $\mathrm{ApoE}^{-/-} \mathrm{HD}+$ Tene mice. It was previously reported that DPP-4 inhibitors significantly suppressed atherosclerotic lesions in the aortic wall of $\mathrm{ApoE}^{-/-}$mice, a representative animal model of atherosclerosis [33, 34].

Our results showed that teneligliptin reduced LOX-1 protein expression in the aortic tissue of $\mathrm{ApoE}^{-/-}$mice. LOX-1 expression was attenuated by inhibitors of PKC and ERK, indicating that increased production of intracellular ROS and activation of the PKC/MAPK pathways are initial signaling events in the regulation of LOX-1 gene [35]. Hu et al. [36] reported that compared with normal vessel tissue or the aortic media of cholesterol-fed rabbits, there was a marked increase in the amount of ERK1/2 proteins from atherosclerotic lesions. In the present study, we found that Pho-ERK expression was attenuated in $\mathrm{ApoE}^{-/-}$ HD + Tene mice, and it is possible that teneligliptin regulates LOX-1 by the phosphor-ERK pathway.

In conclusion, our data establish that teneligliptin contributes to the mitigation of hypercholesterolaemic aortic damage, as shown by downregulation of LOX-1, and suppression of 
lipid deposition and inflammation. These findings provide new insights into the role of teneligliptin in hypercholesterolaemic aortic injury and raise the possibility of a novel therapeutic intervention for the progression of cardiovascular disease.

\section{Acknowledgement}

This work was supported by the Natural Science Foundation of Liaoning Province (No. 2013B020). Hongyang Liu designed this study, Ying Zhang helped in performing experiments, Ying Zhang, Lin Luo and Yingshu Liu analyzed data and interpreted the results of experiments, Nan Wang and Liyue Zhu prepared the figures, Hongyang Liu drafted the manuscript, and Guan Wang and Zuowei Pei helped in revising of manuscript. All authors read and approved the final manuscript.

\section{Statement of Ethics}

We obtained ethical review board approval for this study (KY2017-17).

\section{Disclosure Statement}

This study was supported by the Natural Science Foundation of Liaoning Province (No. 2013B020). The authors declare that they have no competing interests.

\section{References}

1 Piedrahita JA, Zhang SH, Hagaman JR, Oliver PM, Maeda N: Generation of mice carrying a mutant apolipoprotein E gene inactivated by gene targeting in embryonic stem cells. Proc Natl Acad Sci USA 1992;89:44714475.

$\checkmark 2$ Wijeysundera DN, Duncan D, Nkonde-Price C, Virani SS, Washam JB, Fleischmann KE, Fleisher LA: American College of Cardiology American Heart Association Task Force on Practice Guidelines. J Am Coll Cardiol 2014; 22:2406-2425.

-3 Arsenault BJ, Kritikou EA, Tardif JC: Regression of atherosclerosis. Curr Cardiol Rep 2012;4:443-449.

4 Karshovska E, Zhao Z, Blanchet X, Schmitt MM, Bidzhekov K, Soehnlein O, von Hundelshausen P, Mattheij NJ, Cosemans JM, Megens RT, Koeppel TA, Schober A, Hackeng TM, Weber C, Koenen RR: Hyperreactivity of junctional adhesion molecule A-deficient platelets accelerates atherosclerosis in hyperlipidemic mice. Circ Res 2015;116:587-599.

5 Pei Z, Okura T, Nagao T, Enomoto D, Kukida M, Tanino A, Miyoshi K, Kurata M, Higaki J: Osteopontin deficiency reduces kidney damage from hypercholesterolemia in Apolipoprotein E-deficient mice. Sci Rep 2016;6: 28882.

6 Mentlein R: Dipeptidyl-peptidase IV (CD26) - role in the inactivation of regulatory peptides. Regul Pept 1999; 85:9-24.

7 Gorrell MD, Gysbers V, McCaughan GW: CD26: A multifunctional integral membrane and secreted protein of activated lymphocytes. Scand J Immunol 2001;54:249-264.

8 Drucker DJ: The biology of incretin hormones. Cell Metab 2006;3:153-165.

9 Mannucci E, Rotella CM: Future perspectives on glucagon-like peptide-1, diabetes and cardiovascular risk. Nutr Metab Cardiovasc Dis 2008;18:639-645.

10 Ferreira L, Teixeira-de-Lemos E, Pinto F, Parada B, Mega C, Vala H, Pinto R, Garrido P, Sereno J, Fernandes R, Santos P, Velada I, Melo A, Nunes S, Teixeira F, Reis F: Effects of sitagliptin treatment on dysmetabolism, inflammation, and oxidative stress in an animal model of type 2 diabetes (ZDF rat). Mediators Inflamm 2010; 2010:592760.

11 Shah Z, Kampfrath T, Deiuliis JA, Zhong J, Pineda C, Ying Z, Xu X, Lu B, Moffatt-Bruce S, Durairaj R, Sun Q, Mihai G, Maiseyeu A, Rajagopalan S: Long-term dipeptidyl-peptidase 4 inhibition reduces atherosclerosis and inflammation via effects on monocyte recruitment and chemotaxis. Circulation 2011;124:2338-2349. 
Huang CY, Shih CM, Tsao NW, Lin YW, Huang PH, Wu SC, Lee AW, Kao YT, Chang NC, Nakagami H, Morishita R, Ou KL, Hou WC, Lin CY, Shyu KG, Lin FY: Dipeptidyl peptidase-4 inhibitor improves neovascularization by increasing circulating endothelial progenitor cells. Br J Pharmacol 2012;167:1506-1519.

13 Amori RE, Lau J, Pittas AG: Efficacy and safety of incretin therapy in type 2 diabetes: systematic review and meta-analysis. JAMA 2007;298:194-206.

14 Monami M, Lamanna C, Desideri CM, Mannucci E: DPP-4 inhibitors and lipids: systematic review and metaanalysis. Adv Ther 2012;29:14-25.

15 Hashikata T, Yamaoka-Tojo M, Kakizaki R, Nemoto T, Fujiyoshi K, Namba S, Kitasato L, Hashimoto T, Kameda R, Maekawa E, Shimohama T, Tojo T, Ako J: Teneligliptin improves left ventricular diastolic function and endothelial function in patients with diabetes. Heart Vessels 2016;31:1303-1310.

-16 Spady DK, Woollett LA, Dietschy JM: Dietschy, Regulation of plasma LDL-cholesterol levels by dietary cholesterol and fatty acids. Annu Rev Nutr 1993;13:355-381.

17 Jialal I, Devaraj S: The role of oxidized low density lipoprotein in atherogenesis. J Nutr 1996;126:S1053S1057.

18 Ridker PM, Hennekens CH, Buring JE, Rifai N: C-reactive protein and other markers of inflammation in the prediction of cardiovascular disease in women. N Engl J Med 2000;12:836-843.

19 Ridker PM, Cushman M, Stampfer MJ, Tracy RP, Hennekens CH: Inflammation, aspirin, and the risk of cardiovascular disease in apparently healthy men. N Engl J Med 1997;336:973-979.

20 Matsushita K, Yatsuya H, Tamakoshi K, Yang PO, Otsuka R, Wada K, Mitsuhashi H, Hotta Y, Kondo T, Murohara T, Toyoshima H: High-sensitivity C-reactive protein is quite low in Japanese men at high coronary risk. Circ J 2007;71:820-825.

-21 Shimada K, Fujita M, Tanaka A, Yoshida K, Jisso S, Tanaka H, Yoshikawa J, Kohro T, Hayashi D, Okada Y, Yamazaki T, Nagai R; JCAD Investigators: Elevated serum C-reactive protein levels predict cardiovascular events in the Japanese Coronary Artery Disease (JCAD) Study. Circ J 2009;73:78-85.

22 Guo X, Yamada S, Tanimoto A, Ding Y, Wang KY, Shimajiri S, Murata Y, Kimura S, Tasaki T, Nabeshima A, Watanabe T, Kohno K, Sasaguri Y: Overexpression of peroxiredoxin 4 attenuates atherosclerosis in apolipoprotein E knockout mice. Antioxid Redox Signal 2012;10:1362-1375.

-23 Abrass CK: Cellular lipid metabolism and the role of lipids in progressive renal disease. Am J Nephrol 2004; 24:46-53.

24 Glass CK, Witztum JL: Atherosclerosis: the road ahead. Cell 2001;104:503-516.

-25 Vaughan AM, Tang C, Oram JF: ABCA1 mutants reveal an interdependency between lipid export function, apoA-I binding activity, and Janus kinase 2 activation. J Lipid Res 2009;50:285-292.

26 Tao Y, Xiong Y, Wang H, Chu S, Zhong R, Wang J, Wang G, Ren X, Yu J: APOC3 induces endothelial dysfunction through TNF- $\alpha$ and JAM-1. Lipids Health Dis 2016;15:153.

-27 Li W, Fang Q, Zhong P, Chen L, Wang L, Zhang Y, Wang J, Li X, Wang Y, Wang J, Liang G: EGFR inhibition blocks palmitic acid-induced inflammation in cardiomyocytes and prevents hyperlipidemia-induced cardiac injury in mice. Sci Rep 2016;6:24580.

28 Deacon CF, Holst JJ: Dipeptidyl peptidase IV inhibition as an approach to the treatment and prevention of type 2 diabetes: a historical perspective. Biochem Biophys Res Commun 2002;294:1-4.

29 Walker PD, Kaushal GP, Shah SV: The major matrix degrading enzyme in renal tubules, produces a novel nidogen fragment in vitro and in vivo. Kidney Int 1998;53:1673-1680.

30 Sawamura T: An endothelial receptor for oxidized low-density lipoprotein. Nature 1997;386:73-77.

-31 Gao S, Geng YJ: LOX-1: a male hormone-regulated scavenger receptor for atherosclerosis. Vascul Pharmacol 2013;59:138-143.

-32 Hu C: LOX-1 deletion decreases collagen accumulation in atherosclerotic plaque in low-density lipoprotein receptor knockout mice fed a high-cholesterol diet. Cardiovasc Res 2008;79:287-293.

-33 Terasaki M, Nagashima M, Nohtomi K, Kohashi K, Tomoyasu M, Sinmura K, Nogi Y, Katayama Y, Sato K, Itoh F, Watanabe T, Hirano T: Preventive effect of dipeptidyl peptidase-4 inhibitor on atherosclerosis is mainly attributable to incretin's actions in nondiabetic and diabetic apolipoprotein E-null mice. PLoS One 2013; 8:e70933.

-34 Terasaki M, Nagashima M, Watanabe T, Nohtomi K, Mori Y, Miyazaki A, Hirano T: Effects of PKF275-055, a dipeptidyl peptidase-4 inhibitor, on the development of atherosclerotic lesions in apolipoprotein E-null mice. Metabolism 2012;6:974-977.

-35 Li L, Sawamura T, Renier G: Glucose enhances human macrophage LOX-1 expression: role for LOX-1 in glucoseinduced macrophage foam cell formation. Circ Res 2004;94:892-901.

-36 Hu Y, Dietrich H, Metzler B, Wick G, Xu Q: Hyperexpression and activation of extracellular signal-regulated kinases (ERK1/2) in atherosclerotic lesions of cholesterol-fed rabbits. Arterioscler Thromb Vasc Biol 2000; $20: 18-26$. 